\title{
Review Article \\ DNA Methylation Pattern as Important Epigenetic Criterion in Cancer
}

\author{
Mehrdad Ghavifekr Fakhr, Majid Farshdousti Hagh, \\ Dariush Shanehbandi, and Behzad Baradaran \\ Immunology Research Center, Tabriz University of Medical Sciences, Tabriz, Iran \\ Correspondence should be addressed to Behzad Baradaran; behzad_im@yahoo.com
}

Received 3 July 2013; Revised 13 September 2013; Accepted 2 November 2013

Academic Editor: Kenta Nakai

Copyright (C) 2013 Mehrdad Ghavifekr Fakhr et al. This is an open access article distributed under the Creative Commons Attribution License, which permits unrestricted use, distribution, and reproduction in any medium, provided the original work is properly cited.

\begin{abstract}
Epigenetic modifications can affect the long-term gene expression without any change in nucleotide sequence of the DNA. Epigenetic processes intervene in the cell differentiation, chromatin structure, and activity of genes since the embryonic period. However, disorders in genes' epigenetic pattern can affect the mechanisms such as cell division, apoptosis, and response to the environmental stimuli which may lead to the incidence of different diseases and cancers. Since epigenetic changes may return to their natural state, they could be used as important targets in the treatment of cancer and similar malignancies. The aim of this review is to assess the epigenetic changes in normal and cancerous cells, the causative factors, and epigenetic therapies and treatments.
\end{abstract}

\section{Introduction}

All somatic cells possess the same genotype, since they have originated from the growth and division of a common progenitor cell. However, during the differentiation process cells become specialized and obtain a variety of functions and features by expressing and suppressing different sets of genes. Normally these settings are controlled by epigenetic processes. The genetics of changes and cell division is heritable. Epigenetic features are changed during the tumor induction and cancer development with different patterns and characteristics [1].

\section{Background}

The term epigenetics is made of two parts: Greek prefix "epi" which means upon or over and "Genetics" which is the science of genes, heredity, and variations in living organisms. It defines what is occurring in the physical state of the genes and chromatin. This word was first defined by Conrad Hal Waddington as the interaction between genes and their environment that creates the phenotype emphasizing that epigenetic mechanisms are different in response to a given environment. Waddington later pointed out that one of the main characteristics of epigenetic changes will occur in gene expression without any mutations. The nongenetic manifestation of traits in morphology had been introduced by Lamarck many years before Waddington propounded this idea. In this new definition, epigenetics is referred to as those changes in the genes functions which are transmitted through both mitosis and meiosis without causing any alterations in the DNA sequence [2].

\section{Epigenetic Mechanisms}

Epigenetic regulations are derived from the fact that the DNA packaging in the nucleus affects the genes expression directly [3]. In general, the increased condensation of DNA enhances the probability of genes silencing. In return, decreasing compression of DNA leads to its accessibility for transcription machinery and increased expression of genes. Physically, the genome in the eukaryotic cells is packed in chromatin structure which determines its accessibility for functions such as transcription, replication, and DNA repair [4]. In general, three common biochemical mechanisms occur in the cell for epigenetic changes: DNA methylation, histone changes, 
and association of nonhistone proteins such as Polycomb and Trithorax complexes.

\section{DNA Methylation}

In mammals, DNA methylation is a common epigenetic change in DNA. After DNA synthesis, cytosines within the dinucleotide $\mathrm{CpG}$ are methylated at their carbon 5 by DNA methyltransferase (DNMT) (Figure 1). CpGs which undergo methylation could be found either in singular situation or in clusters so-called CpG islands [5]. But if the methylation happens in the promoter region of the genes, it would likely lead to gene silencing [6]. Normally, long-term silencing of genes occurs only in X-linked, imprinted, and germ-cell specific genes. CpG islands of DNA sequence that contain plenty of $\mathrm{C}$ and $\mathrm{G}$ nucleotides are commonly hypermethylated in tumor cells which could result in silencing of tumor suppressor genes [7].

An important step toward understanding the role of DNA methylation is to specify its location in the genome. Nowadays, this can be achieved by utilizing methods developed for genome-wide mapping of $5 \mathrm{mc}$ (5 methylcytosine) such as microarrays or high-throughput sequencing [8].

Data obtained from methylation studies show that cytosine methylation is available throughout the genome of mammals. Moreover, in most of the genomes in which DNA has lower $\mathrm{CpG}$ content, there is a high degree of cytosine methylation while, $\mathrm{CpG}$ islands often remain nonmethylated $[9,10]$.

\section{Histone Changes}

Histone changes include posttranslation modifications in the histone proteins of nucleosomes. The long tail of $\mathrm{N}$ terminus in histones which makes the interaction between neighbor nucleosomes may be affected and undergo a variety of modifications such as lysine and arginine methylation, lysine acetylation, and serine phosphorylation (Figure 2). Histone changes affect the organization of the nucleosomes in higher order DNA packaging [11]. According to Turner, histone modifications are used for scheduling the activity of genes during the stages of differentiation [12].

Nonhistone proteins may affect the chromatin configuration through interacting with DNA and histones. For instance, ATP dependent complexes which rearrange the chromatin structure directly move and relocate nucleosomes along the DNA [13]. The second group of protein complexes propounded in epigenetics includes HP1, Polycomb, and Trithorax groups. These proteins attach to the DNA or especially modified histones and catalyze DNA methylation or other changes in histones; for example, Polycomb protein complex arrests histone methylation by interacting with DNMT and recruits DNA methylation [14]. Transcription factors can also affect the chromatin structure and be involved in the heredity of epigenetic changes during cell division [15].

In brief, the interaction between different epigenetic mechanisms controls the accessibility of genes by the transcription machinery. Epigenetic mechanisms are completely

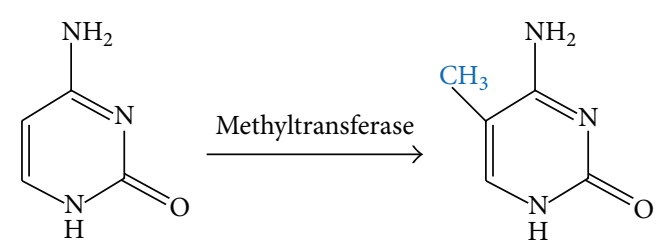

FIGURE 1: Methylation of cytosine in carbon 5.

intertwined in controlling one another and the function of the target genes in an intensifying or attenuating manner which the activities of these genes can be aligned or nonaligned [16].

\section{DNA Methyltransferase Enzymes}

In mammals, DNA methyltransferase enzymes include 4 members in two families which are distinct from each other both structurally and functionally. The DNMT3 family provides the $\mathrm{CpG}$ methylation through de novo path, whilst the DNMT1 family maintains the methylation models during replication [17].

The DNMT3 family includes 2 enzymes DNMT3a and DNMT3b. A regulatory factor similar to DNMT3 enzyme is placed beside these enzymes which is referred to as DNMT3L [18]. DNMT3a and DNMT3b have similar domains. They both have a variable region in the N-terminus and a PWWP domain which probably affects the nonproprietary connection to DNA [19]. Despite possessing homologous structures, they have distinctly proprietary targets [20]. The rate of DNMT3b is very high at the early embryonic period and it is responsible for DNA methylation during implantation [21], whereas DNMT3a is active in the late phases of embryonic period and cell differentiation. DNMT3a also is responsible for DNA methylation in matured gametes $[22,23]$.

DNMT1 enzyme causes methylated models of CpG regions to be copied on new synthesized DNA. Therefore, these changes deemed as epigenetic modifications are inherited during cell division and are hereditary. Recently, obtained data from the DNMT1 structure indicate how DNMT1 connection to hemimethylated CpG region provides DNA accessibility to enzyme catalytic domain whilst link to nonmethylated CpGs protects the new-synthesized fiber by CXXC domain from its methylation. The DNMT1 activity is performed through interaction with Proliferating Cell Nuclear Antigen (PCNA) and Np95 during phase "S" of cell cycle $[24,25]$.

\section{The Role of DNA Methylation and Histone Acetylation in the Regulation of Gene Expression}

Epigenetic mechanisms and modifications play a crucial role in the regulation of gene expression during growth period and cell differentiation. Epigenetic mechanisms may result in gene silencing. This fact has been revealed in many types of human cancers. Despite much research that has been done in 


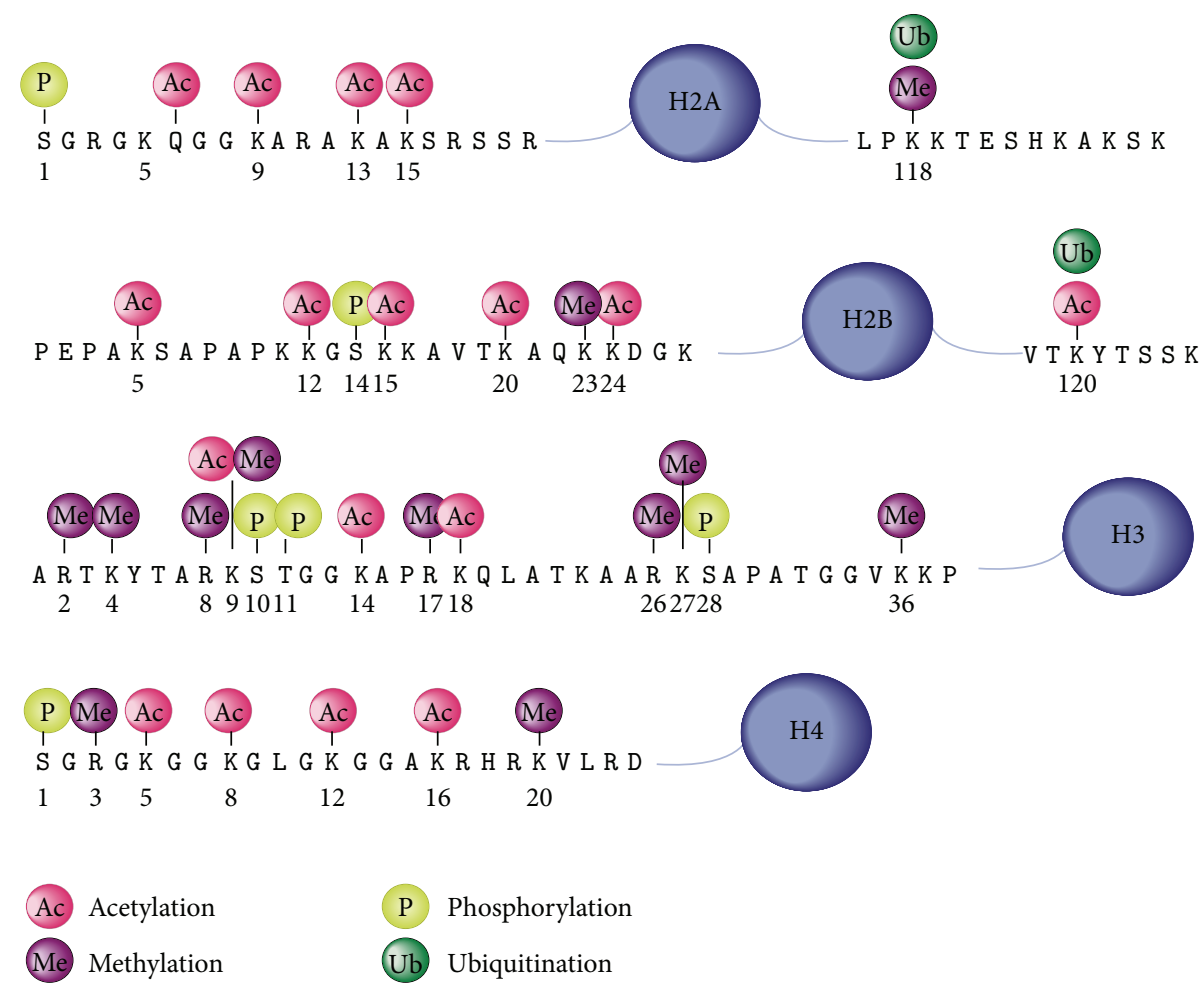

FIGURE 2: Epigenetic modifications of histone amino acids [77].

the field of epigenetics, the role of DNA methylation, histone acetylation, and deacetylation in controlling genes silencing is still not detected correctly.

Today, there are lines of evidence which demonstrate the importance of DNA methylation and histone acetylation in transcription. However, the mechanisms that cause changes in the histone acetylation and methylation of $\mathrm{CpG}$ sites are not completely identified. Similarly, it can be stated that the rise of epigenetic marks in human cancer remains unknown! Whilst it appears that a correct understanding is achieved for maintenance and reserving the DNA methylation patterns after replication by DNMT1 enzyme, the causes of methylated cytosine in $\mathrm{CpG}$ sites remain largely unknown.

It is believed that some DNA sequences are probably identified by DNA methyltransferase enzyme as target. However, there is some evidence proving that the initial DNA sequence causes cytosine methylation in CpG islands [26, 27]. Notwithstanding that the DNMT3a and DNMT3b enzymes are specific to the $\mathrm{CpG}$ island methylation, they seem not to be able to differentiate between the DNA sequences [28].

According to some research, DNA methylation is led by histone modifications $[29,30]$. Today, we know with certainty that transcriptional silencing of genes is directly connected to the amount of histone acetylation and DNA methylation. Nevertheless, the propounded question is whether DNA hypermethylation or histones hypoacetylation leads to gene silencing or epigenetic modifications are consequences of gene silencing. Identifying events that cause inactivation of genes are critical and very important for understanding the mechanisms that lead to cancer; thus, the correct perception of these events ultimately can be helpful in cancer prevention and treatment.

Recent studies show a significant correlation between histones acetylation, DNA methylation, and gene silencing. Since then, interactions between these mechanisms are thought to be likely. In fact, implicit and explicit lines of evidence indicate the connections between histones acetylation and DNA methylation $[26,28,31,32]$. However, it seems that there is still no general consensus that epigenetic modifications can lead to cancer inception.

\section{Relationship between Gene Silencing and Disease}

Any changes made in the genes expression play an important role in the incidence of the disease (or pathogenesis). In some cases, changes in gene expression can result from genetic defects in genes and nucleotide sequences. In some groups of patients, the aberrant epigenetic changes may alter the gene expression. As mentioned earlier, two major epigenetic mechanisms that alter and modify the gene expression are DNA methylation and histone changes [33]. Several changes in the pattern of DNA methylation and silencing the genes that cause various diseases are illustrated in Table 1.

Change in methylation pattern may lead to congenital defects. For example, downregulation of some genes affects the growth rate and changes in the DNMT3b catalytic domain results in immunodeficiency $[33,34]$. 
TABLE 1: Gene silencing proteins and diseases [78].

\begin{tabular}{|c|c|}
\hline Protein & Cellular defect/disease \\
\hline DNMT1 & $\begin{array}{l}\text { Developmental } \\
\text { abnormalities } \\
\text { Igf2 imprinting } \\
\text { Colon cancer } \\
\text { Lymphoma } \\
\text { Pancreatic cancer }\end{array}$ \\
\hline DNMT3B & $\begin{array}{l}\text { Developmental } \\
\text { abnormalities } \\
\text { ICF } \\
\text { Bladder cancer } \\
\text { Breast cancer } \\
\text { Colon cancer } \\
\text { Hepatocellular } \\
\text { carcinoma } \\
\text { Lung cancer }\end{array}$ \\
\hline $\mathrm{MeCP} 2$ & $\begin{array}{l}\text { Chromosome } \\
\text { instability/cell cycle } \\
\text { defects } \\
\text { Breast cancer } \\
\text { Rett syndrome }\end{array}$ \\
\hline $\mathrm{EZH} 2$ & $\begin{array}{l}\text { Cell cycle defects } \\
\text { Barrett's esophagus } \\
\text { Bladder cancer } \\
\text { Breast cancer } \\
\text { Colorectal cancer } \\
\text { Melanoma } \\
\text { Myeloma/lymphoma } \\
\text { Hepatocellular } \\
\text { carcinoma } \\
\text { Prostate cancer } \\
\text { Wilms tumor }\end{array}$ \\
\hline Suv39h1 & $\begin{array}{l}\text { Blood cell defects (RBC and WBC) } \\
\text { Chromosome instability } \\
\text { Chromosome instability/cell cycle defects }\end{array}$ \\
\hline HP1 & $\begin{array}{l}\text { Breast cancer } \\
\text { Medulloblastoma } \\
\text { Papillary thyroid } \\
\text { carcinoma } \\
\text { Viral latency }\end{array}$ \\
\hline
\end{tabular}

\section{Epigenetics in Normal Cells}

The genes functions in eukaryotic cells have been welldefined which can be affected by factors such as growth stage, cell periphery, or other circumstances surrounding the cell. Sequence of genes and their regulatory factors are conserved in initial DNA except for a few variables such as B and T lymphocytes. DNA and its associated proteins are subjected to covalent changes, and the location and pattern of these changes determine the growth phase and cell condition.

9.1. DNA Methylation. DNA methylation plays an important role in controlling cellular processes such as embryonic growth, transcription, inactivation of chromosome $\mathrm{X}$, and determination of gene mapping [35].
In humans, methylation occurs in carbon 5 of cytosine which is positioned before guanine [26]. In normal cells, the $\mathrm{CpG}$ methylation is mainly done in the repetitive regions of genome including satellite regions, endogenous retroviruses, LINEs, and SINEs [36]. CpGs do not exist randomly in the genome, but they are located in GC rich regions referred to as $\mathrm{CpG}$ islands. These islands are usually found at the end of $5^{\prime}$ regulatory regions of many genes [37]. In normal cells, a great part of $\mathrm{CpG}$ islands (about 94\%) is nonmethylated.

Altogether, the CpG island methylation is associated with gene silencing; it has also been shown that methylation of these islands is connected with the histones deacetylation in addition to other factors being involved in genes transcription [38]. The methylation can play a major role in reducing the gene expression as well as inactivation of the $\mathrm{X}$ chromosome in females and chromosome stability through hypermethylation of repetitive sequences [39].

9.2. Histone Changes. Up to now, over 60 histone modifications including acetylation, methylation, phosphorylation, and ubiquitylation have been identified, either by specific antibodies or spectrophotometric techniques [11]. Among all known changes, the lysine methylation shows the highest degree of compression where each methylated region might independently affect the gene activity. In general, the main function of these changes is still unknown. Transcription initiation and elongation are associated with changes of the $\mathrm{N}$-terminal region of nucleosomal $\mathrm{H} 3$ and $\mathrm{H} 4$ histone proteins in the promoter region [40, 41].

Lysine acetylation is generally associated with increased accessibility of chromatin and consequently enhanced activity of transcription enzymes. But the effect of the lysine methylation on histones varies depending on the location where the histone modification has been detected [42]. In addition to regulatory role of histone changes in transcription, it also participates in replication, repair, and organization of DNA [11].

\section{Epigenetics in Cancers}

Today, there are various techniques that reveal the correlation between cancers and epigenetics. They illustrate the connection between the inactivation of microRNAs, genes, and epigenetic changes in cancer progression.

10.1. DNA Methylation. Change of DNA methylation pattern in CpG islands was the first and most significant abnormal epigenetic change identified in cancerous cells. There is a lot of evidence representing the DNA methylation as a change towards the beginning of the carcinogenesis processes. In particular, In particular, in age dependent changes, the DNA methylation pattern may be altered [43]. Age-related modifications can be closely related to the changes in the methylation pattern and the occurrence of cancer in a specific region of the body. Furthermore, in case of the relationship between the environment and the underlying DNA methylation, there is a strong correlation between environmental factors and development of cancer [44]. The DNA methylation pattern in 
cancers is various. Hypomethylation is an extremely common change in association with many cancers such as stomach, kidney, colon, pancreas, liver, and lung [45-47].

Low level methylation in cancers is substantially due to the loss of methylation at repetitive sequences as well as the introns demethylation [48]. During the development of cancer, hypomethylation degree may increase in the DNA and the progressive lesion could participate in the reproduction and metastasis of cancer cells [48].

The following 3 mechanisms have been suggested for DNA hypomethylation: (a) the increased instability of the genome, (b) the reactivation of factors that are capable of movement on DNA, and (c) the functional defect in elements related to genome [49].

Transcription of the regions with a modified methylation pattern which have resulted in hypomethylation would cause the impairment of genome. Hypomethylation of HPV genome in cervical cancer leads to progression of cancer [47]. The reverse can also occur. In such a mode, hypermethylation of tumor suppressor genes in CpG islands as well as in the micro RNA genes leads to inactivation of tumor suppressor genes. The hypermethylation of $\mathrm{CpG}$ islands in promoter region is a crucial incident in the initiation of carcinogenesis process.

Aberrant methylation of CpG islands is also an important factor in the proliferation of tumor cells which leads to silencing of tumor suppressor genes and molecules involved in the cell differentiation. For instance, increased methylation (hypermethylation) of CpG islands within the promoter of tumor suppressor genes is associated with various cancers such as E-cadherin, MLH1, and CDKN2A [49]. Hypermethylation of $\mathrm{CpG}$ islands is associated with silencing of the miRNA. miRNAs are small RNAs with typically 18 to 22 nucleotides, regulating a lot of intracellular functions such as cells reproduction, apoptosis, and cell differentiation [50-52].

10.2. Histone Changes. The relationship between histone changes and cancers is specified after identifying the correlation between cancer and the DNA methylation [46]. Changes in the methylation of $\mathrm{CpG}$ islands could result in various histone modifications and consequently different types of cancers [53]. Independent of $\mathrm{CpG}$ islands methylation, the histone changes can also be directly associated with cancer progression. Activity of many histone acetylase enzymes would result in deacetylation of histone $\mathrm{H} 3$ in the tumor suppressor gene [54]. It seems that there are various pathways that lead to histone modification and cancer development. In some cases, the links between cancers and histone modifications are clearly marked and suggest a direct relationship $[55,56]$.

\section{Impacts of Epigenetic Changes on miRNAs}

Micro RNAs are deemed as a class of small, noncoding, and endogenous RNAs that play a crucial role in gene expression through transcription prevention by induction of a group of regulatory molecules. The miRNA can also be important in

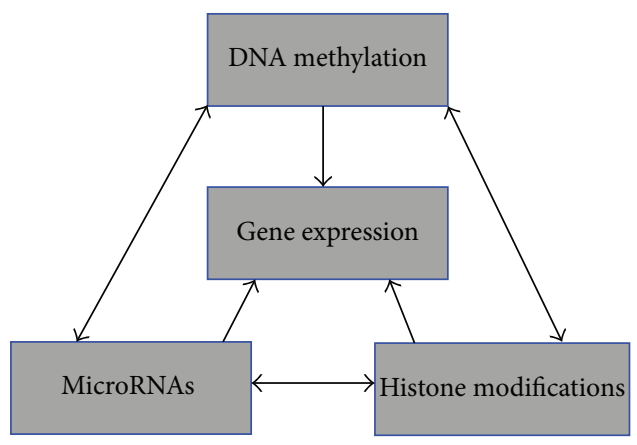

FIGURE 3: Crosstalk between genomic methylation, histone modifications, and the effects of microRNAs on gene expression.

the controlling of the DNA methylation and histone modifications (Figure 3). Epigenetic mechanisms such as promoter methylation and histone acetylation may be adjusted by miRNAs expression. In some pathologic cases such as in cancers, the balance between miRNA and epigenetic processes becomes disordered. The lack of appropriate function of miRNAs and their aberrant expression are associated with the development and progression of human cancers. This process follows cell proliferation and impairment of the apoptosis [57].

Epigenetic changes on genes promoter and miRNAs dependent to the 3-UTR are considered as two important regulatory mechanisms in eukaryotics. Both DNA methylation and miRNAs can suppress the gene expression where miRNAs tend to target the genes with low DNA methylation in their promoter [58]. Recently, it has been shown that epigenetic mechanisms including DNA methylation and histone modifications affect not only gene expression but also the miRNAs. In fact, miRNAs like any other involved genes are affected by similar epigenetic regulations.

Epigenetic abnormalities can increase the rate of miRNA expression in tumor cells, and this increase may lead to the formation of these tumor cells. Almost half of miRNA genes are associated with $\mathrm{CpG}$ islands and their expression can be adjusted by methylation [59]. There are scientific lines of evidence suggesting that epigenetic mechanisms are responsible for regulating more than 100 miRNAs and more than half of them have been identified in the form of methylated specific cancers and about 20 kinds of tumors [60]. miRNAs can be impaired due to abnormal expression of other epigenetic regulatory mechanisms, including the HDACs (histone acetylase) or Polycomb suppressor groups [61].

Incorporation of three methyl groups on lysine 27 of histone $\mathrm{H} 3$ (H3k27me3) and two methyl groups on lysine 79 in histone $\mathrm{H} 3$ ( $\mathrm{H} 3 \mathrm{k} 79 \mathrm{me} 2)$ has been identified in 47 miRNAs (out of 174 miRNAs) in the colorectal cancer cells which is the result of epigenetic mechanisms [62].

Tumor cells often not only show the change in the DNA methylation pattern but also face a lot of histone changes. HDACs are overexpressed in some specific cancers such as CLL and can intervene in the silencing of several miRNA genes, including miR-15a, miR-16, and miR-29b. 


\section{Epigenetic Biomarkers in Cancer}

It has been shown that DNA proprietary methylation especially in $\mathrm{CpG}$ islands can be used as a marker for early cancer detection, disease progression, and prediction of the response to cancer treatment [63].

There are reasons to suggest the methylated tumor suppressor genes as a good diagnostic marker. Some of these reasons include the following: (1) DNA is a stable molecule that can be easily extracted from body fluids and tissues and includes the methylation data; (2) detection of methylation change signals can be considered as an important marker to diagnose gene expression change; however identifying them in normal cells is very difficult; (3) the operating protocols for analyzing the protein or the cDNA expression level are not difficult. Epigenetic biomarkers can be easily extracted from body liquids such as blood, saliva, or urine and used to identify and diagnose tumors at the initial phase of disease [64].

Detection of methylated DNA which is derived from tumors in serum and plasma has shown similar methylation pattern in all kinds of tumors; therefore by tracing these markers, the beginning phase of tumor genesis processes could be detected [63]. Promoter methylation of gene P16 is a good marker for early detection of lung cancer. This marker is detectable and identifiable 3 years prior to the clinical symptoms of cancer [65]. The value of disease prognosis by means of DNA methylation is different in variety of cancers. For instance, in myelodysplastic syndrome, while the prognosis is very weak in the early stage of the disease, promoter methylation of genes $\mathrm{HIC1}, \mathrm{CDH} 1, \mathrm{ER}$, and P15 is diagnosable and traceable [66].

The MGMT gene silencing which is due to methylation in promoter region is an appropriate diagnostic marker in glioblastoma patients [67]. If the functions of DNMT and HDAC suppressors lead to the activation of tumor suppressor genes, then the DNA methylation would be a favorable marker for predicting response to treatment by epidrugs. Further identification of these markers is required for production of epidrugs in the future, but the overall response to the treatment in patients who are being treated by DNMT and HDACs suppressors is not significantly considerable at the present. It should be noted that the focus on the DNA methylation as a marker is essentially applied for early detection of disease and only a very few studies have been done on the assessment of the DNA methylation as a marker for examination of response to treatments by DNMT and HDACs suppressors [68]. It is also known that biomarkers such as different HDAC isoforms and histone acetylation rate are very valuable for prediction of patient response to the treatment by the HDAC suppressors [69].

\section{Epigenetic Treatments}

Upon revealing the aberrant epigenetic changes in malignant cells that lead to tumor suppressor genes silencing, the research has been expanded for achieving new drugs that are able to reactivate the silenced genes due to these changes [70].
Both genetic and epigenetic changes are factors that contribute to cancer development and progression; while the genetic changes are not reversible, epigenetic changes can return to their normal state. Reversibility of epigenetic changes caused the epigenetic treatments to be prioritized among the suggested treatments. The DNA methyltransferase and histone deacetylase enzymes have been assumed to be the most important targets of these treatments. Today, some DNMT and HDACs suppressors have been approved by Food and Drug Administration (FDA) as an anticancer treatment. The use of epigenetic targets is one of the promising ways for the treatment of cancer [71]. Azacitidine and decitabine were the first synthesized drugs for this purpose that suppress the DNMT enzyme. In 2004, FDA approved decitabine (5-aza-2deoxycytidine) as an effective medication for myelodysplastic syndrome. The use of these drugs has remained problematic due to their volatility in water, disruption in the growth and differentiation of myeloid blood cells and side effects such as poisoning is limited [70].

Epigenetic changes allow cancer cells to adapt to their surrounding environment. However, the tumor suppressor genes that are hypermethylated can be reactivated by drugs. Reexpression of hypermethylated genes in the cancer cells is conducted by demethylating agents [72]. DNA demethylating drugs in low doses have antitumor activities. For example, drug 5-azacitidine (Vidaza) has received approval from the FDA for the treatment of leukemia [73-75]. The HDAC enzyme suppressing drugs arrest the cell cycle in differentiation stage. Although, they have demonstrated apoptotic activity in vitro, the specific mechanism has not yet been discovered [76].

All together, the HDAC enzyme suppressors are insignificant in the tumors treatment. Sometimes, DNA demethylating drugs and HDAC suppressors can result in unintended and contradictory consequences because of the increased gene expression. However, achieving epigenetic specific treatments, which directly target transcription factors and gene promoters, has provided a lot of hope for cancer treatment.

\section{Conclusion}

Epigenetics is a hereditable process that affects the gene expression without changing the DNA sequence. Epigenetic processes include DNA methylation and histone and chromatin changes. The importance of epigenetic modifications in cancer is well known. Hence, plenty of research has been conducted in recent years on mechanisms involved in epigenetic changes in cell. Recent advancements in field provide a precise pattern of methylation, acetylation, and miRNA level. These findings have led to the identification of biomarkers in various diseases bringing optimism and hope for curing these diseases in the near future.

\section{References}

[1] E. N. Gal-Yam, Y. Saito, G. Egger, and P. A. Jones, "Cancer epigenetics: modifications, screening, and therapy," Annual Review of Medicine, vol. 59, pp. 267-280, 2008. 
[2] J. Gräff and I. M. Mansuy, "Epigenetic codes in cognition and behaviour," Behavioural Brain Research, vol. 192, no. 1, pp. 7087, 2008.

[3] N. Dillon, "Gene regulation and large-scale chromatin organization in the nucleus," Chromosome Research, vol. 14, no. 1, pp. 117-126, 2006.

[4] C. L. Woodcock, "Chromatin architecture," Current Opinion in Structural Biology, vol. 16, no. 2, pp. 213-220, 2006.

[5] M. L. de Groote, P. J. Verschure, and M. G. Rots, "Epigenetic Editing: targeted rewriting of epigenetic marks to modulate expression of selected target genes," Nucleic Acids Research, vol. 40, no. 21, pp. 10596-10613, 2012.

[6] A. K. Maunakea, R. P. Nagarajan, M. Bilenky et al., "Conserved role of intragenic DNA methylation in regulating alternative promoters," Nature, vol. 466, no. 7303, pp. 253-257, 2010.

[7] C. De Smet, C. Lurquin, B. Lethé, V. Martelange, and T. Boon, "DNA methylation is the primary silencing mechanism for a set of germ line- and tumor-specific genes with a CpG-rich promoter," Molecular and Cellular Biology, vol. 19, no. 11, pp. 7327-7335, 1999.

[8] P. W. Laird, "Principles and challenges of genome-wide DNA methylation analysis," Nature Reviews Genetics, vol. 11, no. 3, pp. 191-203, 2010.

[9] R. Lister, M. Pelizzola, R. H. Dowen et al., "Human DNA methylomes at base resolution show widespread epigenomic differences," Nature, vol. 462, no. 7271, pp. 315-322, 2009.

[10] A. Meissner, T. S. Mikkelsen, H. Gu et al., "Genome-scale DNA methylation maps of pluripotent and differentiated cells," Nature, vol. 454, no. 7205, pp. 766-770, 2008.

[11] T. Kouzarides, "Chromatin modifications and their function," Cell, vol. 128, no. 4, pp. 693-705, 2007.

[12] K. P. Nightingale, L. P. O’Neill, and B. M. Turner, "Histone modifications: signalling receptors and potential elements of a heritable epigenetic code," Current Opinion in Genetics and Development, vol. 16, no. 2, pp. 125-136, 2006.

[13] V. K. Gangaraju and B. Bartholomew, "Mechanisms of ATP dependent chromatin remodeling," Mutation Research, vol. 618, no. 1-2, pp. 3-17, 2007.

[14] B. Schuettengruber, D. Chourrout, M. Vervoort, B. Leblanc, and G. Cavalli, "Genome regulation by polycomb and trithorax proteins," Cell, vol. 128, no. 4, pp. 735-745, 2007.

[15] G.-L. Zhou, D.-P. Liu, and C.-C. Liang, "Memory mechanisms of active transcription during cell division," BioEssays, vol. 27, no. 12, pp. 1239-1245, 2005.

[16] Y. Li, J. Zhu, G. Tian et al., "The DNA methylome of human peripheral blood mononuclear cells," PLOS Biology, vol. 8, no. 11, Article ID e1000533, 2010.

[17] T. Chen and E. Li, "Establishment and maintenance of DNA methylation patterns in mammals," Current Topics in Microbiology and Immunology, vol. 301, pp. 179-201, 2006.

[18] T. H. Bestor, "The DNA methyltransferases of mammals," Human Molecular Genetics, vol. 9, no. 16, pp. 2395-2402, 2000.

[19] S. M. Lukasik, T. Cierpicki, M. Borloz, J. Grembecka, A. Everett, and J. H. Bushweller, "High resolution structure of the HDGF PWWP domain: a potential DNA binding domain," Protein Science, vol. 15, no. 2, pp. 314-323, 2006.

[20] J. Borgel, S. Guibert, Y. Li et al., "Targets and dynamics of promoter DNA methylation during early mouse development," Nature Genetics, vol. 42, no. 12, pp. 1093-1100, 2010.

[21] Y. Kato, M. Kaneda, K. Hata et al., "Role of the Dnmt3 family in de novo methylation of imprinted and repetitive sequences during male germ cell development in the mouse," Human Molecular Genetics, vol. 16, no. 19, pp. 2272-2280, 2007.

[22] M. Kaneda, M. Okano, K. Hata et al., "Essential role for de novo DNA methyltransferase Dnmt3a in paternal and maternal imprinting," Nature, vol. 429, no. 6994, pp. 900-903, 2004.

[23] S. A. Smallwood, S.-I. Tomizawa, F. Krueger et al., "Dynamic CpG island methylation landscape in oocytes and preimplantation embryos," Nature Genetics, vol. 43, no. 8, pp. 811-814, 2011.

[24] J. Song, O. Rechkoblit, T. H. Bestor, and D. J. Patel, "Structure of DNMT1-DNA complex reveals a role for autoinhibition in maintenance DNA methylation," Science, vol. 331, no. 6020, pp. 1036-1040, 2011.

[25] J. Song, M. Teplova, S. Ishibe-Murakami, and D. J. Patel, "Structure-based mechanistic insights into DNMT1-mediated maintenance DNA methylation," Science, vol. 335, no. 6069, pp. 709-712, 2012.

[26] A. Bird, "DNA methylation patterns and epigenetic memory," Genes and Development, vol. 16, no. 1, pp. 6-21, 2002.

[27] M. Okano, D. W. Bell, D. A. Haber, and E. Li, "DNA methyltransferases Dnmt3a and Dnmt3b are essential for de novo methylation and mammalian development," Cell, vol. 99, no. 3, pp. 247-257, 1999.

[28] E. J. Richards and S. C. R. Elgin, "Epigenetic codes for heterochromatin formation and silencing: rounding up the usual suspects," Cell, vol. 108, no. 4, pp. 489-500, 2002.

[29] L. Bartee, F. Malagnac, and J. Bender, "Arabidopsis cmt3 chromomethylase mutations block non-CG methylation and silencing of an endogenous gene," Genes and Development, vol. 15, no. 14, pp. 1753-1758, 2001.

[30] C. M. Papa, N. M. Springer, M. G. Muszynski, R. Meeley, and S. M. Kaeppler, "Maize chromomethylase Zea methyltransferase2 is required for CpNpG methylation," Plant Cell, vol. 13, no. 8, pp. 1919-1928, 2001.

[31] V. Mutskov and G. Felsenfeld, "Silencing of transgene transcription precedes methylation of promoter DNA and histone $\mathrm{H} 3$ lysine 9," EMBO Journal, vol. 23, no. 1, pp. 138-149, 2004.

[32] V. J. Mutskov, C. M. Farrell, P. A. Wade, A. P. Wolffe, and G. Felsenfeld, "The barrier function of an insulator couples high histone acetylation levels with specific protection of promoter DNA from methylation," Genes and Development, vol. 16, no. 12, pp. 1540-1554, 2002.

[33] M. Ehrlich, K. L. Buchanan, F. Tsien et al., "DNA methyltransferase $3 \mathrm{~B}$ mutations linked to the ICF syndrome cause dysregulation of lymphogenesis genes," Human Molecular Genetics, vol. 10, no. 25, pp. 2917-2931, 2001.

[34] K. Delaval, A. Wagschal, and R. Feil, "Epigenetic deregulation of imprinting in congenital diseases of aberrant growth," BioEssays, vol. 28, no. 5, pp. 453-459, 2006.

[35] K. D. Robertson, "DNA methylation and human disease," Nature Reviews Genetics, vol. 6, no. 8, pp. 597-610, 2005.

[36] J. A. Yoder, C. P. Walsh, and T. H. Bestor, "Cytosine methylation and the ecology of intragenomic parasites," Trends in Genetics, vol. 13, no. 8, pp. 335-340, 1997.

[37] F. Antequera and A. Bird, "Number of CpG islands and genes in human and mouse," Proceedings of the National Academy of Sciences of the United States of America, vol. 90, no. 24, pp. 11995-11999, 1993.

[38] L. Lopez-Serra and M. Esteller, "Proteins that bind methylated DNA and human cancer: reading the wrong words," British Journal of Cancer, vol. 98, no. 12, pp. 1881-1885, 2008. 
[39] W. A. Schulz, C. Steinhoff, and A. R. Florl, "Methylation of endogenous human retroelements in health and disease," Current Topics in Microbiology and Immunology, vol. 310, pp. 211-250, 2006.

[40] R. J. Sims III, R. Belotserkovskaya, and D. Reinberg, "Elongation by RNA polymerase II: the short and long of it," Genes and Development, vol. 18, no. 20, pp. 2437-2468, 2004.

[41] R. J. Sims III and D. Reinberg, "Histone H3 Lys 4 methylation: caught in a bind?" Genes and Development, vol. 20, no. 20, pp. 2779-2786, 2006.

[42] R. N. Laribee, N. J. Krogan, T. Xiao et al., "BUR kinase selectively regulates $\mathrm{H} 3 \mathrm{~K} 4$ trimethylation and $\mathrm{H} 2 \mathrm{~B}$ ubiquitylation through recruitment of the PAF elongation complex," Current Biology, vol. 15, no. 16, pp. 1487-1493, 2005.

[43] C. J. Piyathilake, O. Henao, A. R. Frost et al., "Race- and age-dependent alterations in global methylation of DNA in squamous cell carcinoma of the lung (United States)," Cancer Causes and Control, vol. 14, no. 1, pp. 37-42, 2003.

[44] T. M. Edwards and J. P. Myers, "Environmental exposures and gene regulation in disease etiology," Environmental Health Perspectives, vol. 115, no. 9, pp. 1264-1270, 2007.

[45] Y. Akiyama, C. Maesawa, S. Ogasawara, M. Terashima, and T. Masuda, "Cell-type-specific repression of the maspin gene is disrupted frequently by demethylation at the promoter region in gastric intestinal metaplasia and cancer cells," American Journal of Pathology, vol. 163, no. 5, pp. 1911-1919, 2003.

[46] A. P. Feinberg and B. Tycko, "The history of cancer epigenetics," Nature Reviews Cancer, vol. 4, no. 2, pp. 143-153, 2004.

[47] V. Badal, L. S. H. Chuang, E. H.-H. Tan et al., "CpG methylation of human papillomavirus type 16 DNA in cervical cancer cell lines and in clinical specimens: genomic hypomethylation correlates with carcinogenic progression," Journal of Virology, vol. 77, no. 11, pp. 6227-6234, 2003.

[48] M. F. Fraga, M. Herranz, J. Espada et al., "A mouse skin multistage carcinogenesis model reflects the aberrant DNA methylation patterns of human tumors," Cancer Research, vol. 64, no. 16, pp. 5527-5534, 2004.

[49] M. Esteller, "Molecular origins of cancer: epigenetics in cancer," The New England Journal of Medicine, vol. 358, no. 11, pp. 11481159, 2008.

[50] G. A. Calin and C. M. Croce, "MicroRNA signatures in human cancers," Nature Reviews Cancer, vol. 6, no. 11, pp. 857-866, 2006.

[51] C.-Z. Chen, "MicroRNAs as oncogenes and tumor suppressors," The New England Journal of Medicine, vol. 353, no. 17, pp. 17681771, 2005.

[52] B. Zhang, X. Pan, G. P. Cobb, and T. A. Anderson, "microRNAs as oncogenes and tumor suppressors," Developmental Biology, vol. 302, no. 1, pp. 1-12, 2007.

[53] M. F. Fraga, E. Ballestar, A. Villar-Garea et al., "Loss of acetylation at Lys16 and trimethylation at Lys20 of histone H4 is a common hallmark of human cancer," Nature Genetics, vol. 37, no. 4, pp. 391-400, 2005.

[54] R. J. Gibbons, "Histone modifying and chromatin remodelling enzymes in cancer and dysplastic syndromes," Human Molecular Genetics, vol. 14, no. 1, pp. R85-R92, 2005.

[55] Y. Shi, "Histone lysine demethylases: emerging roles in development, physiology and disease," Nature Reviews Genetics, vol. 8, no. 11, pp. 829-833, 2007.

[56] R. J. Klose, Q. Yan, Z. Tothova et al., "The retinoblastoma binding protein RBP2 Is an H3K4 demethylase," Cell, vol. 128, no. 5, pp. 889-900, 2007.
[57] M. V. Iorio, C. Piovan, and C. M. Croce, "Interplay between microRNAs and the epigenetic machinery: an intricate network," Biochimica et Biophysica Acta, vol. 1799, no. 10-12, pp. 694-701, 2010.

[58] Z. Su, J. Xia, and Z. Zhao, "Functional complementation between transcriptional methylation regulation and posttranscriptional microRNA regulation in the human genome," BMC Genomics, vol. 12, supplement 5, article S15, 2011.

[59] M. Esteller, "Epigenetic gene silencing in cancer: the DNA hypermethylome," Human Molecular Genetics, vol. 16, no. 1, pp. R50-R59, 2007.

[60] T. Kunej, I. Godnic, J. Ferdin, S. Horvat, P. Dovc, and G. A. Calin, "Epigenetic regulation of microRNAs in cancer: an integrated review of literature," Mutation Research, vol. 717, no. 1-2, pp. 77-84, 2011.

[61] H. Richly, L. Aloia, and L. Di Croce, "Roles of the Polycomb group proteins in stem cells and cancer," Cell Death and Disease, vol. 2, no. 9, article e204, 2011.

[62] H. Suzuki, S. Takatsuka, H. Akashi et al., "Genome-wide profiling of chromatin signatures reveals epigenetic regulation of microRNA genes in colorectal cancer," Cancer Research, vol. 71, no. 17, pp. 5646-5658, 2011.

[63] H. Shi, M. X. Wang, and C. W. Caldwell, "CpG islands: their potential as biomarkers for cancer," Expert Review of Molecular Diagnostics, vol. 7, no. 5, pp. 519-531, 2007.

[64] S. E. Cottrell and P. W. Laird, "Sensitive detection of DNA methylation," Annals of the New York Academy of Sciences, vol. 983, pp. 120-130, 2003.

[65] W. A. Palmisano, K. K. Divine, G. Saccomanno et al., "Predicting lung cancer by detecting aberrant promoter methylation in sputum," Cancer Research, vol. 60, no. 21, pp. 5954-5958, 2000.

[66] A. Aggerholm, M. S. Holm, P. Guldberg, L. H. Olesen, and P. Hokland, "Promoter hypermethylation of p15INK4B, HIC1, $\mathrm{CDH} 1$, and ER is frequent in myelodysplastic syndrome and predicts poor prognosis in early-stage patients," European Journal of Haematology, vol. 76, no. 1, pp. 23-32, 2006.

[67] M. E. Hegi, A.-C. Diserens, T. Gorlia et al., "MGMT gene silencing and benefit from temozolomide in glioblastoma," The New England Journal of Medicine, vol. 352, no. 10, pp. 997-1003, 2005.

[68] K. Raj, A. John, A. Ho et al., "CDKN2B methylation status and isolated chromosome 7 abnormalities predict responses to treatment with 5-azacytidine," Leukemia, vol. 21, no. 9, pp. 19371944, 2007.

[69] L. Stimson and N. B. La Thangue, "Biomarkers for predicting clinical responses to HDAC inhibitors," Cancer Letters, vol. 280, no. 2, pp. 177-183, 2009.

[70] H. M. Kantarjian, S. O'Brien, J. Cortes et al., "Results of decitabine (5-aza- $2^{\prime}$ deoxycytidine) therapy in 130 patients with chronic myelogenous leukemia," Cancer, vol. 98, no. 3, pp. 522528, 2003.

[71] F. F. Cai, C. Kohler, B. Zhang et al., "Epigenetic therapy for breast cancer," International Journal of Molecular Sciences, vol. 12, no. 7, pp. 4465-4487, 2011.

[72] C. B. Yoo and P. A. Jones, "Epigenetic therapy of cancer: past, present and future," Nature Reviews Drug Discovery, vol. 5, no. 1, pp. 37-50, 2006.

[73] C. I. Müller, B. Rüter, H. P. Koeffler, and M. Lübbert, "DNA hypermethylation of myeloid cells, a novel therapeutic target in MDS and AML," Current Pharmaceutical Biotechnology, vol. 7, no. 5, pp. 315-321, 2006. 
[74] Y. Oki, E. Aoki, and J.-P. J. Issa, "Decitabine-Bedside to bench," Critical Reviews in Oncology/Hematology, vol. 61, no. 2, pp. 140152, 2007.

[75] G. S. Mack, "Epigenetic cancer therapy makes headway," Journal of the National Cancer Institute, vol. 98, no. 20, pp. 1443-1444, 2006.

[76] J. E. Bolden, M. J. Peart, and R. W. Johnstone, "Anticancer activities of histone deacetylase inhibitors," Nature Reviews Drug Discovery, vol. 5, no. 9, pp. 769-784, 2006.

[77] S. Kato, K. Inoue, and M. Y. Youn, "Emergence of the osteoepigenome in bone biology," IBMS BoneKEy, vol. 7, no. 9, pp. 314-324, 2010.

[78] T. J. Moss and L. L. Wallrath, "Connections between epigenetic gene silencing and human disease," Mutation Research, vol. 618, no. 1-2, pp. 163-174, 2007. 

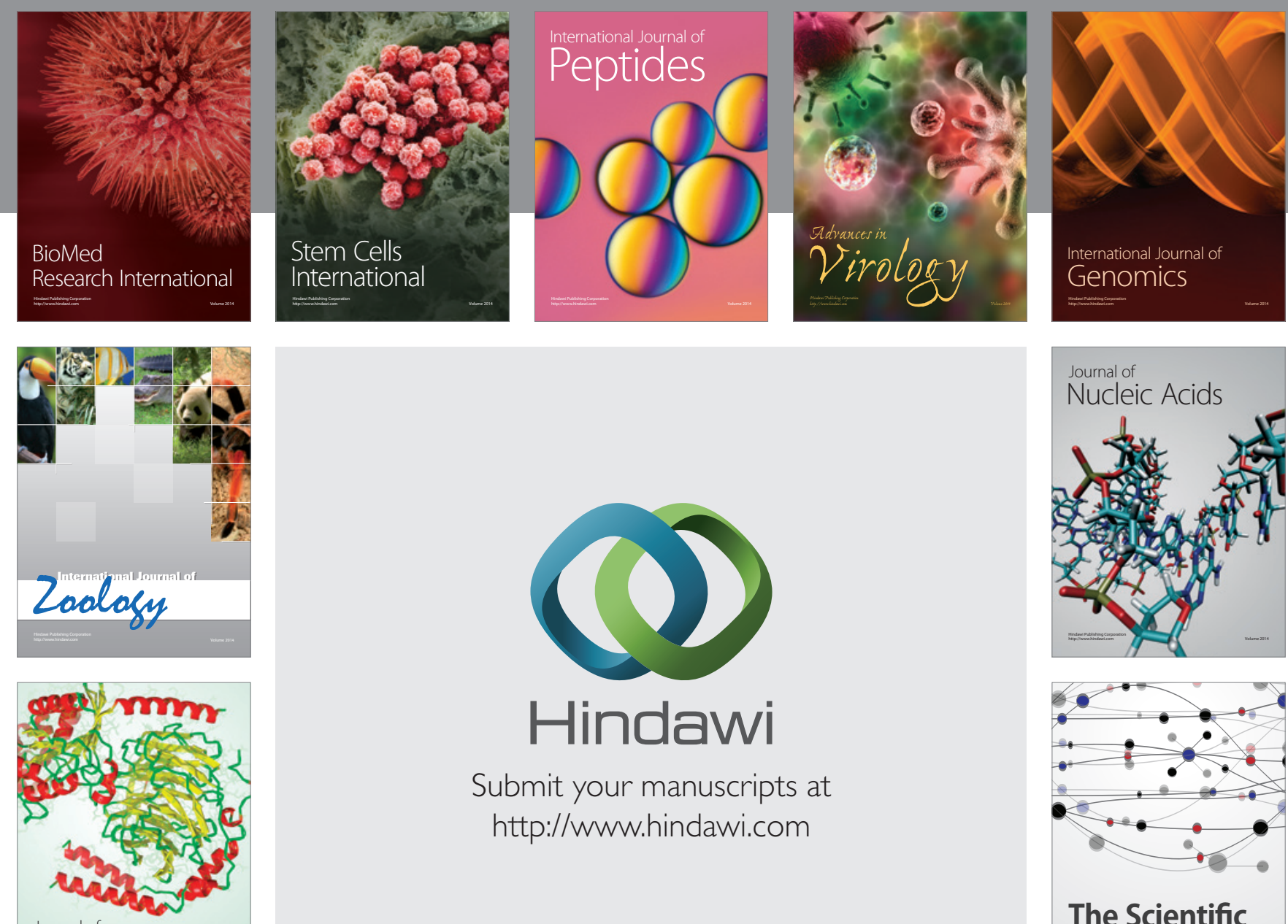

Submit your manuscripts at

http://www.hindawi.com

Journal of
Signal Transduction
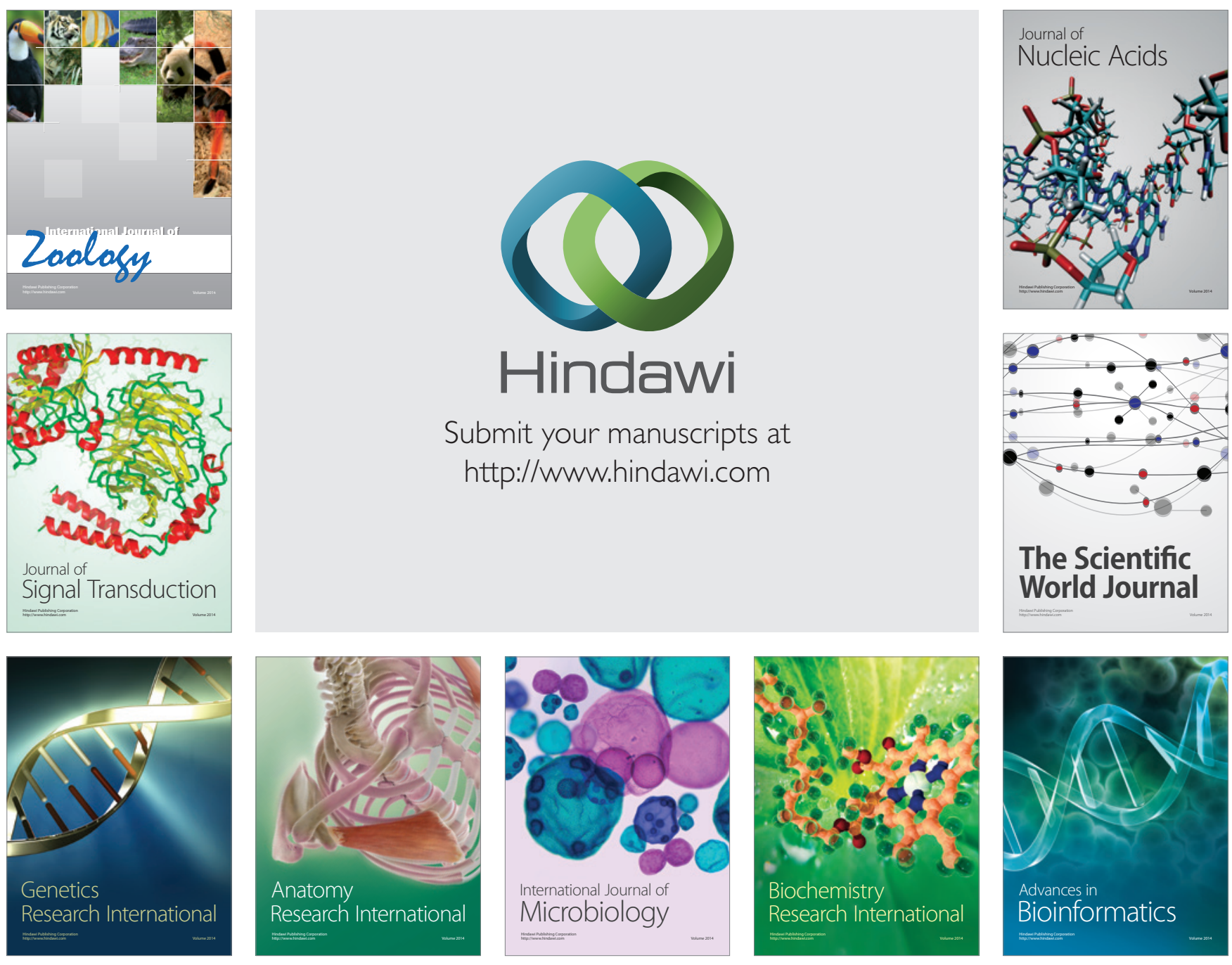

The Scientific World Journal
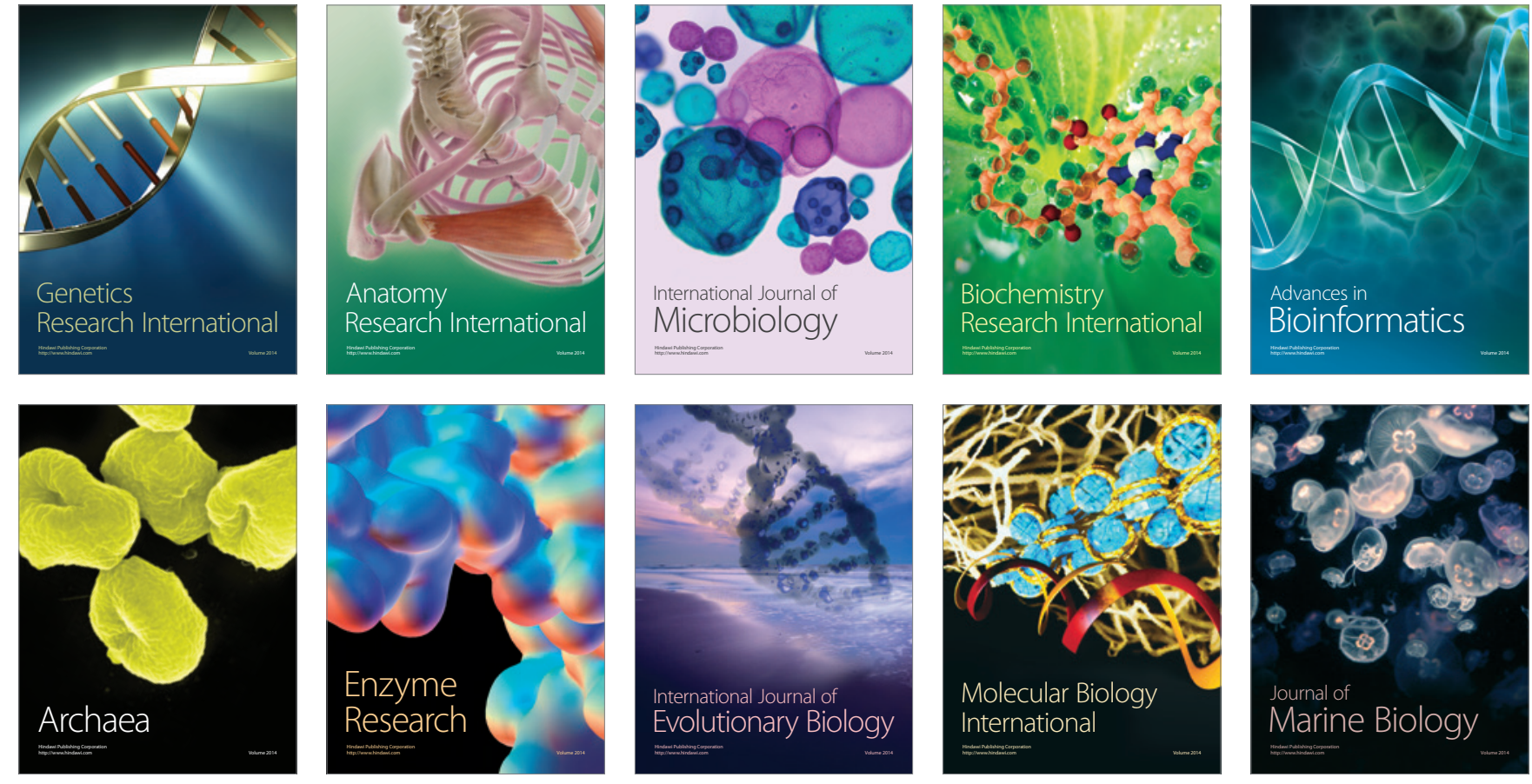